\title{
RESEARCH ON ALGORITHM OF BOREHOLE RESISTIVITY IMAGING METHOD
}

\author{
Benyu Su, Jingcun Yu, Maofei Li
}

Original scientific paper

Traditional dc electrical exploration method will face great challenge when detecting deep, complex geologic target. With the purpose, forward modelling and inverse modelling method of borehole resistivity has been developed. According to the characters of geology, the geological model has been set up. The numerical simulation shows that borehole resistivity method is a very deep, complex geo-model. Therefore, this research provides a new idea for exploring deep, complex target of geo-electrical model.

Keywords: borehole resistivity method; coal mine goaf; forward modelling; inverse modelling

\section{Istraživanje algoritma metode prikazivanja otpora bušotine}

Izvorni znanstveni članak

Tradicionalna metoda istraživanja istosmjerne struje suočit će se s velikim izazovom kad se otkrije duboki, složeni geološki cilj. U tu svrhuje razvijena je metoda unaprijednog modeliranja i inverznog modeliranja otpora bušotine. U skladu s geološkim značajkama, postavljen je geološki model. Numerička simulacija pokazuje da je metoda otpora bušotine vrlo dubok, složen geo-model. Stoga ovo istraživanje daje novu ideju za istraživanje dubokog, složenog cilja geo-električnog modela.

Ključne riječi: inverzno modeliranje; metoda otpora bušotine; otpad u rudniku; unaprijedno modeliranje

\section{Introduction}

In this paper we will talk about using the technique of borehole direct current resistivity imaging to study the mining goaf. The direct current resistivity inversion has been researched as a geophysical exploration technique for a long time. In the early 1900's, Slichter [1] set up the resistivity prospecting method for horizontal structure. Firstly, direct current resistivity inversions were based on the assumption that the geo-electrical structure is 1-D or $2-\mathrm{D}$. But actually underground structure is 3-D. As well known, inversion result of 3-D model is very different from that of $1-\mathrm{D}$ or $2-\mathrm{D}$. And inversion by $1-\mathrm{D}$ or $2-\mathrm{D}$ model cannot present features of underground geoelectrical structure. With the help of computer development, 3-D resistivity inversion becomes possible and needed. During the last several decades, many 3-D inversion methods have been suggested. Petrick et al. [2] gave a method based on alpha centres. Li and Oldenburg [3] used Born equation for DC responses. Sasaki [4] proposed an inversion method based on reciprocity for efficient evaluations of Jacobian matrix. Hatanaka et al. [5] proposed an inversion method based on homogeneous model for evaluations of Jacobian matrix, and Marquardt equation was proposed as non-linear least squares method to inversion. However, these 3-D resistivity inversion methods are available for shallow detecting and they cannot accurately inverse anomalous body for the deep earth. For borehole resistivity research, Pidlisecky et al. [6] elaborated using borehole resistivity method to monitor the diffusion contamination beneath the factory. In addition, $\mathrm{Su}$ et al. $[7,8]$ have finished the forwarding of borehole resistivity method.

\section{Methods}

\subsection{Inverse problem}

3-D resistivity inversion is a normal 3-D resistivity inversion. As we know, resistivity inversion problem can be expressed as
$\Delta d=A \Delta p$

where $\Delta \boldsymbol{d}$ is the vector of difference between observed data and model responses. $\boldsymbol{A}$ is the Jacobian matrix and $\Delta \boldsymbol{p}$ is the vector of difference between parameters in this iteration and in the previous iteration.

In non-linear least squares method, parameters can be obtained by many iterations using Marquardt equation which can be expressed as

$\left(\boldsymbol{A}^{\mathrm{T}} \mathrm{A}+\lambda \boldsymbol{C}^{\mathrm{T}} \boldsymbol{C}\right) \Delta \boldsymbol{p}=\boldsymbol{A}^{\mathrm{T}} \Delta \boldsymbol{d}$,

where $\lambda$ is the damping factor, $\boldsymbol{C}$ is the smooth factor. In this step, roughly estimated resistivity structures are needed, so Jacobian matrix is approximately estimated in homogeneous earth proposed by Loke and Baker as follows

$$
\begin{aligned}
& A_{i, j}=\frac{\partial \rho_{a j}}{\partial \rho_{i}}=G \cdot \frac{\partial \phi_{j}}{\partial \rho_{i}} \cdot \frac{1}{I} \\
& G=2 \pi \cdot \sqrt{\left(x_{c}-x_{p}\right)^{2}+\left(y_{c}-y_{p}\right)^{2}+z_{c}^{2}}
\end{aligned}
$$

where $\rho_{a j}$ is apparent resistivity, $p_{i}$ and $\rho_{i}$ are equivalent parameters of block resistivity, $G$ is the geometric factor, $\phi$ is the electric potential and $I$ is electric current. By applying the reciprocity principle, Tripp et al. [10] proposed the sensitivity theorem to solve the partial derivatives. The sensitivity matrix is expressed as

$$
\frac{\partial \phi}{\partial \rho}=\int_{\tau} J J^{\prime} \mathrm{d} \tau=\rho^{2} \int_{\tau} \nabla \phi \nabla \phi^{\prime} \mathrm{d} \tau,
$$

where $\tau$ is the volume, and volume range is

$$
\left\{(x, y, z) \mid x_{1} \leq x \leq x_{2}, y_{1} \leq y \leq y_{2}, z_{1} \leq z \leq z_{2}\right\} .
$$


The volume size is expressed as

$V_{\tau}=\left(x_{2}-x_{1}\right)\left(y_{2}-y_{1}\right)\left(z_{2}-z_{1}\right)$.

$J$ is current density from a point source at the transmitter and $J^{\prime}$ is current density from a point source at the receiver. Source positions at the transmitter and at the receiver can be expressed as $\left(x_{c}, y_{c}, z_{c}\right)$ and $\left(x_{p}, y_{p}, 0\right)$ respectively. And position vectors from subsurface point $(x, y, z)$ are expressed as follows

$$
\begin{aligned}
& r_{c 1}=\left(x-x_{c}, y-y_{c}, z_{c}\right) . \\
& r_{c 2}=\left(x-x_{c}, y-y_{c}, z_{c}\right) . \\
& r_{p}=\left(x-x_{p}, y-y_{p}, z\right) .
\end{aligned}
$$

Hamilton operators are expressed as

$$
\nabla \varphi=-\frac{\rho \cdot I}{4 \pi} \cdot\left(\frac{r_{c 1}}{\left|r_{c 1}\right|^{3}}+\frac{r_{c 2}}{\left|r_{c 2}\right|^{3}}\right)
$$

The left side of Eq. (4) becomes

$$
\frac{\partial \phi}{\partial \rho}=-\frac{I}{8 \pi^{2}} \cdot\left(\int_{\tau} \frac{r_{c 1}}{\left|r_{c 1}\right|^{3}}-\frac{r_{p}}{\left|r_{p}\right|^{3}}+\frac{r_{c 2}}{\left|r_{c 2}\right|^{3}}-\frac{r_{p}}{\left|r_{p}\right|^{3}}\right) \mathrm{d} \tau .
$$

Because the range of normalized volume $\tau$ is from -1 to 1 , Eq. (9) can be rewritten as

$$
\frac{\partial \phi}{\partial \rho}=\frac{I \cdot V_{\tau}}{64 \pi^{2}} \cdot \int_{-1-1}^{1} \int_{-1}^{1} \int_{-1}^{1} f(u, v, w) \mathrm{d} u \mathrm{~d} v \mathrm{~d} w
$$

where $f(u, v, w)$ is the normalized function. The part of integration in Eq. (10) can be estimated based on GaussLegendre integration as follows

$$
\int_{-1}^{1} \int_{-1-1}^{1} \int_{-1}^{1} f(u, v, w) \mathrm{d} u \mathrm{~d} v \mathrm{~d} w=\sum_{k=1}^{n} \sum_{j=1}^{n} \sum_{i=1}^{n} \omega_{i} \omega_{j} \omega_{k} f\left(\alpha_{i} \alpha_{j} \alpha_{k}\right)
$$

Table 1 Parameters

\begin{tabular}{|c|c|c|}
\hline$N$ & Abscissas $(\alpha)$ & Weights $(\omega)$ \\
\hline \multirow{2}{*}{2} & $-0,5773502692$ & 1,00000000 \\
& 0,5773502692 & 1,00000000 \\
\hline \multirow{2}{*}{3} & $\pm 0,7745966692$ & 0,55555556 \\
& 0,0000000000 & 0,88888888 \\
\hline \multirow{2}{*}{4} & $\pm 0,8611363116$ & 0,34785485 \\
& $\pm 0,3399810436$ & 0,65214515 \\
\hline \multirow{3}{*}{5} & $\pm 0,9061798459$ & 0,23692689 \\
& $\pm 0,5384693101$ & 0,47862867 \\
& 0,00000000000 & 0,56888889 \\
\hline
\end{tabular}

As well known, resistivity inversion problem can be expressed as Eq. (12):

$$
e=D-G\left(m^{k+1}\right)=D-G\left(m^{k}+\Delta m\right) .
$$

Here, $D$ is the measured voltages and $G$ is calculated voltages by changing $m$ which is geologic resistivity parameters for forward calculation.

For the Eq. (1), it can be rewritten into Eq. (13) by introducing regularization theory.

$\Phi=\left\|\boldsymbol{W}_{D}(G-D)-\boldsymbol{W}_{D} J_{A} \Delta m\right\|^{2}+\mu\left\|\boldsymbol{W}_{m} \Delta m\right\|^{2}$

Here, $\boldsymbol{W}_{D}$ and $\boldsymbol{W}_{m}$ are weighting parameters matrix of measurement voltage and model parameters, respectively.

Based on Eq. (14), the minimum optimization function can be expressed using Eq. (3):

$$
\left(J_{A}^{\mathrm{T}} \boldsymbol{W}_{D}^{\mathrm{T}} \boldsymbol{W}_{D} J_{A}+\mu \boldsymbol{W}_{m}^{\mathrm{T}} \boldsymbol{W}_{m}\right) \Delta m=J_{A}^{\mathrm{T}} \boldsymbol{W}_{D}^{\mathrm{T}} \boldsymbol{W}_{D}(D-G) .
$$

Now we simplify Eq. (15) to Eq. (16):

$$
\bar{A} \Delta m=\Delta \bar{D}
$$

Here, $\bar{A}=\left[\begin{array}{c}\boldsymbol{W}_{D} J_{A} \\ \sqrt{\mu} \boldsymbol{W}_{m}\end{array}\right], \bar{D}=\left[\begin{array}{c}\boldsymbol{W}_{D}(G-D) \\ 0\end{array}\right]$.

Eq. (16) can be solved using singular-value decomposition. And the $\Delta m$ is added to the initial vector $\boldsymbol{m}_{0}$. The procedure is repeated until a misfit between the measured and model data is reduced to an acceptable RMS level to obtain the updated parameters.

The repeated procedure as shown using Eq. (17).

$$
m=m^{(0)}+\Delta m
$$

\subsection{Forward problem}

The application of the finite-difference method to the $3-\mathrm{D}$ resistivity problem is thoroughly discussed in $\mathrm{Su}$ et al. [10] and Dey and Morrison [11]. However, measurement array is considered in the borehole in this study. Hence the method will be briefly outlined in this section.

These voltages and currents are related to the subsurface conductivity structure via the following relationship, as described in Eq. (18):

$\nabla(-\sigma \nabla \phi)=I \cdot\left[\delta\left(r-r_{s^{+}}\right)-\delta\left(r-r_{s-}\right)\right]$.

Voltages $(\phi)$ can be calculated via solving Eq. (18) by inputting current $(I)$. Here, $\sigma$ is conductivity of earth. $\delta\left(r-r_{s^{+}}\right)$and $\delta\left(r-r_{s^{-}}\right)$are Dirac delta corresponding to positive and negative current source, respectively.

Based on Eq. (18), Eq. (19) can be obtained by integral computation.

$$
\begin{aligned}
& \iint_{\Delta V_{i, j, k}} \int \nabla[\sigma(x, y, z) \nabla \phi(x, y, z)]= \\
& =I \cdot\left[\delta\left(r-r_{s^{+}}\right)-\delta\left(r-r_{s-}\right)\right] .
\end{aligned}
$$

Using Green's theorem, the volume integral becomes 


$$
\iint_{\Delta V_{i, j, k}} \int \nabla(\sigma \nabla \phi) \mathrm{d} v=\int_{S_{i, j, k}} \int \sigma \frac{\partial \phi}{\partial \eta} \mathrm{d} s .
$$

For the Eq. (8), the finite difference method can be employed to discrete [11]. Findlay, Eq. (18) can be expressed using finite difference matrix.

$$
K u=s,
$$

where $K$ is a large, sparse and banded system matrix, $u$ is a vector consisting of the unknown solutions of the total potentials at all nodes, and $s$ represents the impressed source.

\section{Results}

As well known, the geological model of goaf can be described using Fig. 1 which shows that the zones with low resistivity caused by leaking water are fracture zone, caving zone and goaf, respectively. Hence, during the procedure of numerical modelling we use the model, as shown in Fig. 2. The resistivity value of the zone containing leaking water is given $5 \Omega / \mathrm{m}$ and background resistivity is given $100 \Omega / \mathrm{m}$. The numerical model is shown in Fig. 2 where the small circles indicate electrodes which are emplaced in four boreholes which are A, B, C and $\mathrm{D}$ and there are six electrodes in each borehole. We adopt dipole-pole acquisition technique which involves one pair of current electrodes and one pole of electrical potential between each of the six borehole pairs $(\mathrm{AB}, \mathrm{AC}$, $\mathrm{AD}, \mathrm{BC}, \mathrm{BD}$ and $\mathrm{CD}$ ), as in Fig. 2.

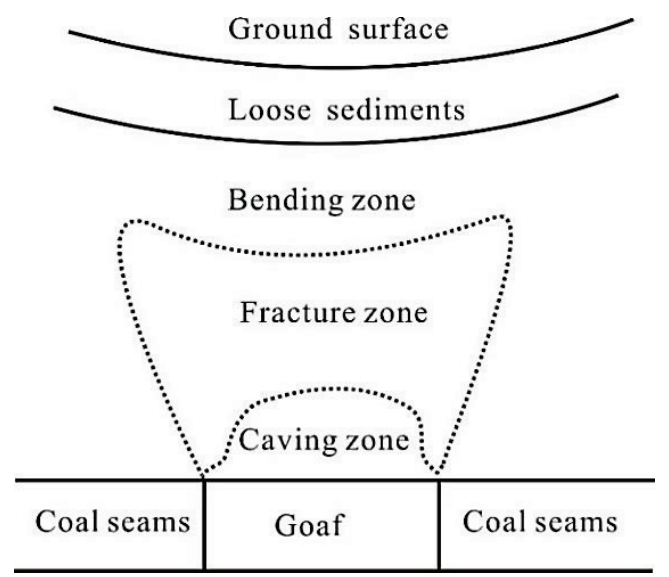

Figure 2 The geologic model of goaf. The original earth is changed into three zones: Bending zone, fracture zone and caving zone, respectively. Meanwhile, ground surface has been sunk.

The example of detail for measurement between current electrodes and potential electrode is shown in Fig. 3. Here, electrodes in the borehole A as current electrodes and electrodes in the borehole B as potential electrodes. Hence, for only consideration of measurement between borehole A and borehole B, 15 independent current pairs are involved in borehole A. Every pair current electrode is connected by curve. For each of these pairs, the data are recorded at 6 electrodes in the borehole B. For the measurement between borehole $\mathrm{A}$ and borehole $\mathrm{B}, 90$ data will be obtained. Therefore, total of 540 data points are obtained for the entire survey including borehole pairs of $\mathrm{AB}, \mathrm{AC}, \mathrm{AD}, \mathrm{BC}, \mathrm{BD}$ and $\mathrm{CD}$.

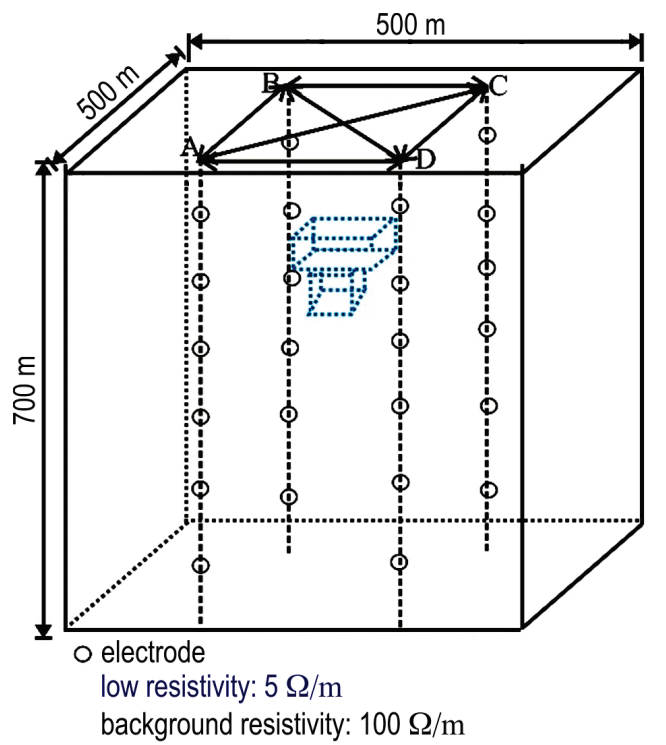

Figure 3 Numerical model of Fig. 1 and acquisition technique. The area closing with blue dotted line indicates geological abnormity body, while small circle is electrodes.

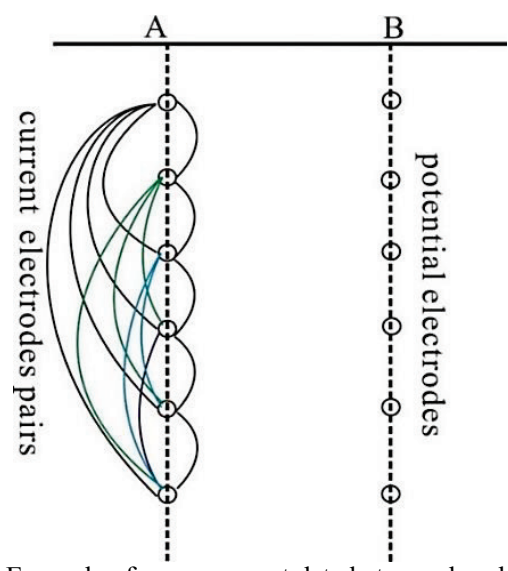

Figure 3 Example of measurement data between borehole A and borehole B.

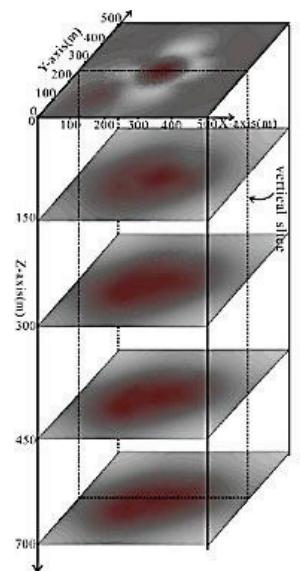

(a)

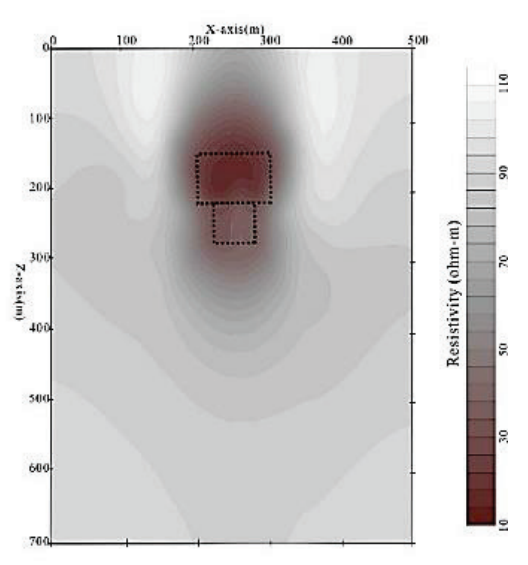

(b)
Figure 5 (a) Horizontal cross-section slices of modelling results. According to the slices, in the centre the low resistivity abnormality areas indicate the position of geological abnormity body in horizontal direction. Due to the volume effect, the vertical direction in the centre of model exhibits low resistivity abnormality. (b) Vertical slice of 3D data volume and the vertical slice position closing with dotted line is shown in Fig. 4a. In Fig. 4b, the area closed with the dotted line indicates the position of geological abnormity body. 
As shown in Fig. 3, two electrodes of each pair are connected by curve in borehole $\mathrm{A}$, and one electrode is negative electrode and the other is positive electrode. Electrodes in borehole B are potential electrodes. Hence, acquisition technique of the dipole-pole (two electrodes to be current electrodes, one electrode to be potential electrode) is employed.

Based on the model as shown in Fig. 2, the modelling results are shown in Fig. 5. Here, Fig. 5a is composed of five cross-section slices of different depth. However, Fig. $5 b$ is depth slice of (X-Z section). With help of Fig. 5a, the area of geological abnormity body in horizontal direction can be analysed. Due to the volume effect, the depth boundaries of geological abnormity body cannot accurately be analysed only depending on the depth slice. However, depth slice, as shown in Fig. 5b, can help us to analyse the area of geological abnormity body in vertical direction

\section{Conclusions}

Based on the fundamental theory of direct current resistivity forward modelling and inverse modelling, technique of borehole resistivity imaging has been developed. In addition, the technique of borehole resistivity imaging has been introduced into research of investigating goaf. Numerical simulations show that the borehole resistivity imaging is very valid for exploring deep and complex geological targets. Therefore, this research provides a new idea for exploring the goaf for the coal mines.

\section{Acknowledgements}

This research was funded by Fundamental Research Funds for the Central Universities (NO. 2014QNA88).

\section{Reference}

[1] Slichter, L. B. The interpretation of the resistivity prospecting method for horizontal structures. // Physics. 4(1933), pp. 307-322. DOI: 10.1063/1.1745198

[2] Petrick, W. R.; Sill, W. R.; Ward, S. H. Three-dimensional resistivity inversion using alpha centers. // Geophysics. 46(1981), pp. 1148-1163. DOI: 10.1190/1.1441255

[3] Li, Y.; Oldenburg, D. W. Approximate inverse mappings in DC resistivity problems. // Geophysical Journal International. 109(1992), pp. 343-362. DOI: 10.1111/j.1365246X.1992.tb00101.x

[4] Sasaki, Y. 3-D resistivity inversion using the finite-element method. // Geophysics. 59(1994), pp. 1893-1848. DOI: 10.1190/1.1443571

[5] Hatanaka, H.; Aono, T.; Mizunaga, H. et al. (Threedimensional modeling and inversion of the mise-a-la-masse data using a steel-casing borehole. // Proc. World Geothermal, 2005.

[6] Pidlisecky, A.; Haber, E.; Knight, R. RESINVM3D: A 3D resistivity inversion package. // Geophysics. 72(2007), pp. H1-H11. DOI: 10.1190/1.2402499

[7] Su, B. Y.; Fujimitsu, Y. A model study of residual oil distribution jointly using crosswell and borehole-surface electric potential methods. // Applied Geophysics. 9 (2012), pp. 19-26. DOI: 10.1007/s11770-012-0309-5

[8] Su, B. Y.; Fujimitsu Y. Surface-borehole electric potential survey in layered media and its applications. // Journal of
Central South University. 19(2012), pp. 1109-1115. DOI: 10.1007/s11771-012-1116-0

[9] Loke, M. H.; Barker, R. D. Practical techniques for 3D resistivity surveys and data inversion. // Geophysical Prospecting. 44(1996), pp. 499-523. DOI: 10.1111/j.13652478.1996.tb00162.x

[10] Tripp, A. C.; Hohmann, G. W.; Swift, C. M. Twodimensional resistivity inversion. // Geophysics. 49(1984) pp. 1708-1717. DOI: 10.1190/1.1441578

[11] Song, Y. B. Sunk horizontal line-current situation of Chinese goaf. // View of Times, 2009.

[12] Dey, A.; Morrison, H. F. Resistivity modelling for arbitrarily shaped three dimensional Structures. // Geophysics. 44, 4(1979), pp. 753-780. DOI: $10.1190 / 1.1440975$

\section{Authors' addresses}

Benyu Su, Assistant professor

Institute of Applied Geophysics, The School Resource and Earth Science, State Key Laboratory for Geomechanics \& Deep Underground Engineering, China University of Mining and Technology, Xuzhou, 221116, China subenyu@cumt.edu.cn

Jingcun Yu, professor Corresponding author Institute of Applied Geophysics, The School Resource and Earth Science, State Key Laboratory for Geomechanics \& Deep Underground Engineering, China University of Mining and Technology, Xuzhou, 221116, China yujingcuncumt@126.com

Maofei Li, Master student

Institute of Applied Geophysics, The School Resource and Earth Science, China University of Mining and Technology, Xuzhou, 221116, China

lmfzxx@126.com 